\title{
Study on Relationship between Selected Independent Variables with Knowledge of the Mobile Agro-Advisory Services Using Farmers of Udupi District of Karnataka
}

\author{
Navinkumar $^{1}$, B. Dhananjaya ${ }^{2}$ and T.H. Ranjith ${ }^{3}$ \\ ${ }^{1}$ UAHS, M.Sc.(Agri), Department of Agricultural Extension Education, Shivamogga, Karnataka, India \\ ${ }^{2} \mathrm{KVK}$, Programme Co-ordinator, Brahmavar, Udupi, Karnataka, India \\ ${ }^{3}$ ZAHRS, Technical Officer GKMS, Brahmavar, Udupi, Karnataka, India
}

"Correspondence author: navinkumar1323@gmail.com (ORCID ID: 0000-0002-9632-9657)

Received: $10-04-2019$

Revised: $15-07-2019$

Accepted: 20-08-2019

\begin{abstract}
The present study was conducted during 2016-17 in the Udupi district of Karnataka. Mobile phones play an important role in accessing the information about improved cultivation practices. In this study, we had analysed the relationship between independent variable and knowledge level of the farmers. We had selected total 13 independent variables for the study, three variables viz., education, achievement motivation and risk orientation showed positive and significant relationship at one per cent level of probability. Whereas, six variables viz., annual income, extension contact, scientific orientation,extension participation, mass media participation and innovativeness showed positive and significant relation at five per cent level of probability with knowledge level. The remaining four variables namely, age, family type, occupation and land holding and did not showed any significant relationship with knowledge level.

Highlights

(0 The knowledge level of the farmers about mobile agro-advisory services had improve by some selected independent variables viz., annual income, extension contact, scientific orientation, extension participation, mass media participation and innovativeness.
\end{abstract}

Keywords: Mobile, Knowledge, variables, Mobile, SMS

In most developing countries, agriculture is the main source of the population's income. Usually farmers plan agricultural production with the instruments of their knowledge. A good knowledge about the exact production techniques will enables farmers to increase their production and productivity of the crops. In this perspective the services of knowledge provided by the Village Resource Centres and other institutions is expected to a have positive impact on the farmers' productivity. In order to understand the level of knowledge of farmers we are taking a case of pest management. Pest management is embarked upon for the promotion of yields of crops (Ofuoku et al. 2009). Knowledge on the methods to be adopted for controlling pests. In this case also VRC attendees have good knowledge than others. 61.9 percent of them have perfect knowledge regarding this. 34.5 percent have incomplete knowledge, 3 percent are not sure about this and only 0.6 percent is ignorant. In case of VRC non-attendees in Meppadi, 20.1 percent have perfect knowledge, 46 percent have incomplete knowledge and 23.4 percent are not sure about and 10.4 percent are ignorant. Only 1.2 percent of VRC non-attendees of neighbouring villages have the perfect knowledge regarding the methods for control pests. 68.3 percent have just incomplete knowledge and 17.1 percent are not sure about it (Shaijumon, 2014). Lack of access to 
AESRA

relevant in formations leads to low yields, famers stress and low income. Nowadays Information and Communication Technologies (ICTs) have the potential to transform agriculture in rural area. Smart phones and it applications has come with great innovations. The applications have been developed to help farmers reduce stress, acquire relevant information on good agriculture practices, weather, quality input, markets tendency, etc. Through social media, web sites and other applications, farmers can improve their skills, share experiences and even sale their products online using their smart phones. So, despite the multiple smart phones applications and web site put in place for agriculture development, this is going to best impact if these constraints are being taking into consideration. Nevertheless, most people in rural area often communicate through simple mobile phone which are less expensive and affordable. Validation of SMS content among the respondents and reported that as far as mean scores were concerned, highest mean score (2.60) was given to SMS content was related to needs of the farmers, followed by SMS bridges the information gap (2.44), SMS content was easily understood (2.32) etc., and the usefulness of SMS varied from practice to practice. About 72.00 per cent of the respondents reported that the SMS regarding fertilizer application was most useful followed by insect and disease management (70.0\%) (Sangeetha et al. 2016). Smart phones and their applications are innovations bringing good solution for agriculture development in other to help farmers to have access to relevant in formations. It participates in the amelioration of agriculture extension work and advisory services. With this the study, has been conducted with the objective to assess the relationship between selected independent variables with Knowledge of the Mobile agro-Advisory Services Using farmers.

\section{METHODOLOGY}

The present study was conducted during 2016-17 in the Udupi district of Karnataka. The farmers who are registered for mobile agro-advisory services for receiving all agricultural information through SMS were considered as target group for the study. There were 4000 registered Agro-met Advisory users and 1400 registered users in KVK. Among those 40 farmers from each existing three taluks viz. Udupi,
Karkala \& Kundapur were selected as respondents for the study. Thus, the sample size of the study comprises of 120 respondents. The knowledge of the farmers had analysed by using the "Teacher made test" suggested by Anastasi (1961) was employed to measure the knowledge level of respondents. All the important information sending to farmers through messages were listed separately in consultation with the experts. The questions and answers were carefully framed. The answers elicited from the farmers were quantified by giving ' 1 ' score to correct and ' 0 ' to wrong answers. Based on the response obtained, the knowledge level was quantified by using frequency and percentage.

Karl Pearson's product movement correlation coefficient (Simple correlation coefficient) was employed as to assess the relationship between the dependent and independent variables.

The correlation coefficient was computed by using the following formula,

$$
r=\frac{n \Sigma x y-(\Sigma x)(\Sigma y)}{\sqrt{\left(n \Sigma x^{2}-(\Sigma x)^{2}\left(n \Sigma y^{2}-(\Sigma y)^{2}\right)\right)}}
$$

Where,

$$
\begin{aligned}
& r=\text { Simple correlation coefficient } \\
& \Sigma x=\text { Sum of } x \text { values } \\
& \Sigma y=\text { Sum of } y \text { values } \\
& \Sigma x^{2}=\text { Sum of square of } x \text { value } \\
& \Sigma y^{2}=\text { Sum of square of } y \text { value } \\
& (\Sigma y)^{2}=\text { Square of sum of } y \text { value } \\
& \Sigma x y=\text { Sum of } x y \text { values } \\
& n=\text { Number of pair of observation }
\end{aligned}
$$

\section{RESULTS AND DISCUSSION}

The correlation coefficient of the personal, socioeconomic and psychological variables with knowledge level of the farmers has been furnished in Table 1.

It could be observed from Table 1 that, out of total 13 independent variables selected for the study, three variables viz., education, achievement motivation and risk orientation showed positive and significant relationship at one per cent level of probability. Whereas, six variables viz., annual income, extension contact, scientific 
orientation, extension participation,mass media participation and innovativeness showed positive and significant relation at five per cent level of probability with knowledge level. The remaining four variables namely, age, family type, occupation and land holding and did not showed any significant relationship with knowledge level.

\section{Age and knowledge}

It was observed from the Table 1 that, Age was found to be non-significantly related with the knowledge level of the farmers. This inferred that farmers of different age group had different knowledge level. As mobile is one of the ICT tool, it needs continuous usage to get the updated information so it differs from young age group to old age group. The above findings were in conformity with the findings of Arun Kumar and Meti (2013).

\section{Education and knowledge}

It was evident from the Table 1 that, Education was found to be positive and significantly related with knowledge level of the farmers. The majority of the farmers are literates, they can use and operate mobile and read all the messages sent to them. This may be the reason for positive and significantly relation between education and knowledge level of the farmers. The above findings were in conformity with the findings of Subhashchandra (2007).

\section{Family type and knowledge}

It could be seen from the Table 1 that, family type was found to be non-significantly related with the knowledge level of the farmers. As the mobile, could be used by any individual farmer who ever it may be it does not matters the type of family as nuclear or joint family. The above findings were in conformity with the findings Raghuprasad et al. (2013).

\section{Occupation and knowledge}

It was observed from the Table 1 that, occupation was found to be non-significantly related with the knowledge level of the farmers. This type of result might be due to the fact that, even non-agriculture occupation people are using the mobile agroadvisory services more than the person actually cultivating the land. The above findings were in conformity with the findings Moulasab (2004).

\section{Land holding and knowledge}

It was evident from the Table 1 that, land holding was found to be non-significantly related with the knowledge level of the farmers. The messages are sending to all the farmers irrespective of the land holding. Since Udupi district is said to be small farmers district and having more number of small and marginal farmers, so this might be the reason for land holding and knowledge are non-significant. The above findings were in conformity with the findings Raghuprasad et al. (2013).

\section{Annual income and knowledge}

It could be seen from the Table 1 that, annual income was found to be positive and significantly related with knowledge level of the farmers. The probable reason might be that, the high-income farmers are always see messages sent to them because they want to do something innovative compare to others. Thus, their knowledge certainly improves. The above findings were in conformity with the findings Kadu et al. (2013).

\section{Scientific orientation and knowledge}

It was observed from the Table 1 that, scientific orientation was found to be significantly related with the knowledge level of the farmers. This might be due to the fact that respondents in the study area are highly educated. However, scientific methods require much skill and knowledge and the information sending to the farmers are scientific and updated. The above findings were in conformity with the findings Vinaya Kumar et al. (2013).

\section{Extension contact and knowledge}

The results presented in the Table 1 revealed that, extension contact was found to be positive and significantly related with knowledge level of the farmers. The probable reason might be that, the farmers are regularly contact the agricultural experts and the various agricultural departments. Thus, the extension contact and knowledge are directly proportional and significantly related each other. The above findings were in conformity with the findings of Moulasab et al. (2006).

\section{Extension participation and knowledge}

It was observed from the Table 1 that, extension 


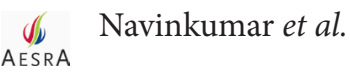

participation was found to be positive and significantly related with knowledge level of the farmers. The probable reason might be that, the farmers are involved in all the extension activities like field trips, field day, training programmes and krishimela might have directly helped them to gain the knowledge.

The above findings were in conformity with the findings Raghuprasad et al. (2013).

\section{Mass media participation and knowledge}

It was evident from the Table 1 that, mass media participation was found to be positive and significantly related with knowledge level of the farmers. The probable reason might be that, the majority of the framers are literate, so they have more interest in current issues and new technology. Mass media also provides enormous opportunity for repeated exposure to new technologies and motivating farmers to acquire knowledge.

The above findings were in conformity with the findings Raghuprasad et al. (2013).

\section{Innovativeness and knowledge}

It could be seen from the Table 1 that, innovativeness was found to be positive and significantly related with knowledge level of the farmers. The probable reason might be that, farmers are highly innovative they practice all the information sent to them and regularly use the mobile to get the information so the knowledge and innovativeness are significantly related each other.

The above findings were in contrast with the findings Raghuprasad et al. (2013).

\section{Achievement motivation and knowledge}

It was observed from the Table 1 that, achievement motivation was found to be positive and significantly related with knowledge level of the farmers. Achievement motivation is very important from the point of knowledge, once decided to achieve, they will achieve the knowledge required for the same. That is why they have gained knowledge through mobile messages.

The above findings were in contrast with the findings Moulasab et al. (2006).

\section{Risk orientation and knowledge}

It was evident from the Table 1 that, risk orientation was found to be positive and significantly related with knowledge level of the farmers. The probable reason might be that, the farmers have high risk bearing ability, so they try to do something new in their farming, hence they regularly use to see the mobile message. The above findings were in conformity with the findings of Moulasab et al. (2006).

Table 1: Relationship between selected independent variables and their knowledge level $(n=120)$

\begin{tabular}{ccc}
\hline S1. No & Categories & r- value \\
\hline 1 & Age & $0.127^{\mathrm{NS}}$ \\
2 & Education & $0.275^{* *}$ \\
3 & Family type & $0.065^{\mathrm{NS}}$ \\
4 & Occupation & $0.059^{\mathrm{NS}}$ \\
5 & Land holding & $0.017^{\mathrm{NS}}$ \\
6 & Annual income & $0.227^{*}$ \\
7 & Scientific orientation & $0.218^{*}$ \\
8 & Extension contact & $0.221^{*}$ \\
9 & Extension participation & $0.188^{*}$ \\
10 & Mass media participation & $0.215^{*}$ \\
11 & Innovativeness & $0.202^{*}$ \\
12 & Risk orientation & $0.280^{* *}$ \\
13 & Achievement motivation & $0.284^{* *}$ \\
\hline
\end{tabular}

* Significant at $5 \%$ level of probability; ${ }^{* *}$ Significant at $1 \%$ level of probability. NS- Non-Significant.

\section{CONCLUSION}

Knowledge and information are widely considered as key drivers of economic growth and it is clear that information and communication technologies (ICTs) are deeply involved in flow of knowledge and information to the farming communities. Access to appropriate knowledge and information is an overriding factor for successful natural resource management (NRM) planning and adoption of mobile agro advisory information and it is known to be one of the most important determinants of agricultural productivity. Institutional innovations play a critical role in technology transfer. As technology develops over the period of time, the process of technology transfer also takes different dimensions. 


\section{ACKNOWLEDGEMENTS}

The study was conducted under University of Agricultural and Horticultural Sciences Shivamogga for M.Sc. (Agri) research. The University has provided fund for conducting research under Staff Research Project (SRP) and KVK and ZAHRS Udupi had helped me to conduct research in Udupi, for that am thankful to them.

\section{REFERENCES}

Anastasi, A. 1961. Psychological testing. The Mcmillan Co, New York.

Arun Kumar, P. and Meti, S.K. 2013. Knowledge level of women dairy entrepreneurs about improved dairy management practices. Res. J. Animal Husbandry and Dairy Sci., 4(1): 23-27.

Kadu, S.S., Kotikhane, R.R. and Nagawade, D.R. 2013. Empowerment of women's SHG through food processing and dairy management practices. Indian Res. J. Ext. Edu., 13(3): 52-54.

Moulasab, I. 2004. A study on knowledge and adoption of improved cultivation practices by mango growers of North Karnataka. M. Sc. (Agri.) Thesis, University of Agricultural Sciences Dharwad.

Moulasab, I., Jahagirdar, K.A., Hrevenkangoudar, L.V. and Chandargi, D.M. 2006. A Study on knowledge level of improved cultivation practices by mango growers of North Karnataka. Kar. J. Agric. Sci., 19(2): 435-436.
Ofuoku, A.U., Egho, E.O. and Enujeke, E.C. 2009. Integrated pest management (IPM) adoption among farmers in central agroecological zone of delta state: Nigeria. Advances in Biological Research, 3(1-2): 29-33.

Raghuprasad, K.P., Devaraja, S.C. and Gopala, Y. M. 2013. An analysis of knowledge level of farmers on utilization of ICT tools for farm communication. J. Rural Development, 32(3): $301-310$.

Sangeetha, V., Roy Burman, R., Sharma, J.P. and Dubey, S.K. 2016. Institutional innovations in technology transferMobile agro advisory services and its impact in adopting improved cultivation practices. Economic Affairs, 61(3): 525-532.

Shaijumon, C.S. 2014. Role of ICT Institutions in Enhancing Productivity, Knowledge and Innovativeness of Farmers: A Case Study of ISRO Village Resource Centres. Economic Affairs, 59(1): 63-74.

Subhashchandra, G.A. 2007. An analysis of KVKs managed by university of agricultural sciences, Dharwad and NGO in Karnataka. Ph.D. Thesis, University of Agricultural Sciences Dharwad.

Vinaya Kumar, H.M., Mahatab Ali, K.M., Sujay Kumar, S., Ramanna, K.N. and Govinda Gowda, V. 2013. Personal and socio-psychological characteristics of the beneficiary farmers of community based tank management project and their relationship with socio-economic status. IJABR., 3(2): 184-187. 
